\title{
DESARROLLO Y ESTANDARIZACIÓN DE UNA PRUEBA DE ELISA INDIRECTA PARA BRUCELOSIS OVINA
}

\author{
Domingo Ruelas C. ${ }^{1}$ y Raúl Rosadio A. ${ }^{2}$
}

\section{Abstract}

An indirect enzyme linked immunosorbent assay (I-ELISA) to detect antibodies against Brucella ovis was developed and standardized. The study was carried out at the Microbiology Laboratory of the Faculty of Veterinary Medicine, San Marcos University. A hot saline extract of a Brucella ovis strain was isolated from a ram with clinical epididymitis and prepared. The assay was validated using sera from 74 rams suffering from epididymitis and confirmed by bacterial isolation, as well as negative sera from 75 uninfected rams. The following standard parameters were established: a) polysterene microplates with flat bottomed wells, b) conjugate (rabbit immunoglobulin anti sheep IgG-peroxidase) dilution of $1: 2000, c)$ antigen dilution of $1: 400$, and d) serum dilution of 1: 200 . The maximal intraplate and interplate coefficient of variation (CV) values were $16.7 \%$ and $15.9 \%$, respectively. Receiver-operator characteristic (ROC) analysis indicated a cutoff value of 23.89 . The application of this value to both the positive and negative sera I-ELISA values yielded a diagnostic sensitivity of $97.3 \%$ and a diagnostic specificity of $98.6 \%$, with a $95 \%$ confidence interval of $90.6-99.6$ and $92.8-99.8$, respectively. It is concluded that this validated assay provides a useful alternative for the diagnosis of ovine brucellosis.

Key words: Brucella ovis, epididimitis, ELISA.

\section{Resumen}

Se desarrolló y estandarizó una prueba de ELISA indirecta (ELISA-I) para la detección de anticuerpos contra Brucella ovis. El antígeno (extracto salino) de Brucella ovis, fue preparado a partir de una cepa aislada de un carnero con epididimitis clínica procedente de una empresa ganadera de la sierra central del Perú. La prueba ELISA-I fue validada examinando 74 sueros positivos procedentes de carneros con epididimitis clínica y positivos al aislamiento bacteria y 75 sueros negativos procedentes de carneros sin lesiones testiculares. Las estandarizaciones determinaron los siguientes parámetros: uso de microplacas de poliestireno de 96 celdas de fondo plano, dilución del conjugado (1:2000), dilución del antígeno (1:400), dilución de los sueros (1:200). Los valores máximos del coeficiente de variación (CV) intra e interplaca fueron $16.07 \%$ y $15.95 \%$, respectivamente. El análisis de las características del operador-receptor (ROC) indicó que el punto de corte se encuentra en $\mathbf{2 3 . 8 9 \%}$ de positividad (PP). Consecuentemente ELISAI tuvo una sensibilidad diagnóstica del $97.3 \%$ y una especificidad diagnóstica del $98.6 \%$, 90.6-99.6. Se concluye que la prueba desarrollada es una buena alternativa diagnóstica para brucelosis ovina.

Palabras claves: Brucella ovis, epididimitis, ELISA. 


\section{Introduceion}

La ganadería ovina constituye una alternativa económica importante para la creciente población rural de la sierra central y sur del país, regiones donde los extensos pastizales naturales sirven para la explotación extensiva de ovinos y camélidos sudamericanos. Sin embargo, la ganadería ovina, al igual que cualquier otra industria pecuaria, se encuentra sujeta a factores limitantes tales como la baja eficiencia reproductiva, cuya causa fundamental es la brucelosis ovina (Paolicchi et al., 1992 Homse et al., 1992).

La epididimitis de los carneros es altamente prevalente en casi todos los establecimientos ovejeros del país (Ameghino, 1988). El agente etiológico, Brucella ovis, coloniza preferentemente los órganos genitales causando en los carneros epididimitis crónica asociada a infertilidad (Paolicchi et al., 1992; Jub, 1992). En borregas gestantes produce placentitis desencadenando el aborto al término de la preñez o disminuyendo la vitalidad de los neonatos (Ameghino, 1988; Robles, 1995).

El control de la enfermedad está basado en las prácticas de diagnóstico y eliminación de reproductores positivos (Rosadio, 1978; Blaha, 1995; Robles, 1995). En este contexto, la identificación de los reproductores infectados es importante. La palpación testicular es el método clínico usual para identificar lesiones epidídimales; sin embargo, debe tenerse presente que no todos los carneros infectados presentan epididimitis palpable ni toda epididimitis es causada por Brucella ovis (OIE, 1995). Por lo que es imperativo usar otras técnicas diagnósticas tales como: la prueba de inmunodifusión en gel (IDG) y la prueba de fijación del complemento (FC). Sin embargo, las citadas pruebas presentan ciertas limitaciones, así por ejemplo la IDG, posee baja sensibilidad $(91 \%)$ y requiere de considerable cantidad de antígeno, y la FC es tediosa de realizar
(Rahaley et al., 1984; Worhington et al., 1984). Por lo que estas pruebas vienen siendo reemplazadas a nivel internacional por inmunoensayos como ELISA (Nielsen et al., 1996).

La ELISA es una técnica altamente sensitiva, específica, versátil y es ampliamente utilizado en medicina veterinaria para el diagnóstico de numerosas enfermedades (Guerrero y Calderón, 1985). Adicionalmente, ELISA permite discriminar gran número de muestras, requiere de pequeñas cantidades de reactivos biológicos (Sumption, 1996), y es capaz de proveer de resultados correctos aún cuando se utilizan sueros hemolizados (Spencer y Burges, 1984).

Para el diagnóstico de la brucelosis ovina, han sido estandarizadas varias pruebas de ELISA. Se desarrolló una prueba de ELISA-1, utilizando como antígeno el extracto salino de Brucella ovis con sensibilidad y especificidad (muy cercanos al 100\%), mayores que la IDG y PFC (Worthington et al., 1984; Walker et al., 1985). Así mismo, una prueba similar al anterior, fue capaz de identificar carneros que eliminaban Brucella ovis en el semen, pero que reaccionaban negativamente en FC (Spencer y Burges, 1984). El uso de estas pruebas evitó la permanencia de portadores intraprediales de la enfermedad (Alonso et al., 1995). El país no tiene experiencia en el uso de ELISA en brucelosis ovina (Rosadio, comunicación personal), por lo que se vió la necesidad de estandarizar una prueba de ELISA que sirva como alternativa diagnóstica en brucelosis ovina.

El presente trabajo fue diseñado con el objetivo de desarrollar y estandarizar una prueba de ELISA indirecta (ELISA-I), utilizando como antígeno, el extracto salino de una cepa nacional Brucella ovis, y evaluar su aplicación para la detección de anticuerpos específicos a $B$. ovis. 


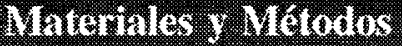

\section{Lugar de Estudio}

Las muestras de sangre para la obtención de los sueros y las de semen para los aislamientos bacteriales, procedieron de dos establecimientos ovejeros: La Cooperativa Comunal "Sacra Familia" de Cerro de Pasco y el Centro Experimental Chuquibambilla, Universidad Nacional del Altiplano: Los aislamientos bacteriales de las muestras de semen procedentes del primero, se efectuaron en el Laboratorio de Microbiología de la Estación IVITA El Mantaro; y del segundo, en el Laboratorio de Microbiología de la Facultad de Medicina Veterinaria y Zootecnia, UNA-Puno. La preparación del antígeno de B. ovis, la estandarización y la aplicación de la prueba de ELISA-I se realizaron en el Laboratorio de Microbiología de la Facultad de Medicina Veterinaria, Universidad Nacional Mayor de San Marcos, Lima.

\section{Reactivos biológicos utilizados en ELISA-I.}

\section{Preparación de antígeno de Brucella ovis.}

El aislamiento de Brucella ovis se obtuvo de muestras de semen de carneros con epidimitis clínica obtenidos mediante electroeyaculación. Estas muestra fueron cultivadas en agar sangre con $10 \%$ de $\mathrm{CO}_{2}$ a $37^{\circ} \mathrm{C}$ por 96 horas. Las células de $B$. ovis del cultivo de una de las cepas aisladas, fueron cosechadas con solución salina al $0.85 \%$ en una cabina de seguridad. Una suspensión celular posteriormente fue lavada centrifugando tres veces en la misma solución salina. Después del último lavado, el paquete celular fue resuspendido en solución salina en una proporción de 1:10 (peso húmedo/volumen) y autoclavada a $120^{\circ} \mathrm{C}$ por 15 minutos. La suspensión, después de ser enfriada a temperatura ambiental, fue centrifugada a 10,000 x g a $4^{\circ} \mathrm{C}$ por $20 \mathrm{~min}$. El sobrenadante recuperado fue dializado contra agua destilada por 48 $\mathrm{h}$ a $4^{\circ} \mathrm{C}$ en agitación constante y renovando agua destilada cada 6 horas. Finalmente el antígeno fue distribuido en alícuotas de $1 \mathrm{ml}$, mantenidas en congelamiento $\mathrm{a}-20^{\circ} \mathrm{C}$ hasta su utilización.

\section{Sueros}

Entre los sueros positivos de referencia $(n=74), 25$ procedieron del banco de sueros del Laboratorio de Microbiología de la Facultad de Medicina Veterinaria, UNMSM, 29 de la Cooperativa Comunal "Sacra Familia" de Cerro de Pasco, y 20 del Centro Experimental Chuquibambilla, Universidad Nacional del Altiplano. Estos sueros fueron procedentes de carneros con epididimitis clínica y cuyo estado de infección fue comprobada por aislamiento bacterial.

Los sueros negativos de referencia $(n=75)$ procedieron de ovinos del establecimiento ovejero "Rigoranch" del distrito de Cieneguilla, Lima. Ninguno de estos animales tenían alteraciones testiculares. Estos sueros fueron negativos a anticuerpos de $B$. ovis al ser examinadas mediante IDG. Además en Cieneguilla no hay historia de presentación de epididimitis a Brucella ovis en carneros.

\section{Conjugado}

Se utilizó globulina de conejo anti IgG ovino unido a la peroxidasa de rábano picante procedente de los Laboratorios CAPPEL-USA. El conjugado fue reconstituido de su forma liofilizada en $2 \mathrm{ml}$ de agua destilada dando una concentración de $12 \mathrm{mg} / \mathrm{ml}$, la suspensión fue diluida preliminarmente en una proporción de 1:10 en una solución $50 \%$ agua-glicerol y almacenada a $-20^{\circ} \mathrm{C}$ para su uso posterior en ELISA.

\section{Estandarización de ELISA-I.}

La estandarización de ELISA-I, se realizó según los parámetros recomendados por el Organismo Internacional de Energía Atómica (IAEA/FAO), incluyendo el uso de las soluciones tampón, así como el tiempo y 
temperatura de incubación de los reactivos en las fases de ELISA.

\section{Optimización de los reactivos biológicos.}

Los reactivos biológicos (antígeno, suero, y conjugado) fueron titulados utilizando el método, de "tablero de ajedrez" en microplacas de poliestireno dotadas de celdas de fondo plano. Para lo cuál, se utilizaron diluciones seriadas dobles del antígeno (desde 1:50 hasta 1:51200), conjugado (desde $1: 200$ hasta 1:25600) y del suero (desde 1:50 hasta 1:6400): Se consideró como dilución óptima de cualquiera de los reactivos mencionados, cuando estos desarrollaron densidad óptica (DO) cercano a 1 a los $15 \mathrm{~min}$. después de la adición del sustrato-cromógeno $\left(\mathrm{H}_{2} \mathrm{O}_{2}+\mathrm{ABTS}\right)$.

\section{Estimación de la repetibilidad de ELISA-I.}

La repetibilidad del ensayo fue inferida a partir de la variabilidad (coeficiente de variación) intra e interplaca de los resultados de ELISA-I de 12 sueros tomados aleatoriamente entre las muestras positivas de referencia. Cada muestra tuvo 8 réplicas intraplaca, y se realizaron 6 sesiones diferentes utilizando los mismos sueros (réplicas interplaca).

\section{Determinación de los sueros control.}

Para identificar los sueros control fuertemente positivo $(\mathrm{C}++)$ y débilmente positivo $(\mathrm{C}+)$, se utilizaron los resultados de ELISA-I de los 12 sueros arriba citados. La selección de $\mathrm{C}++$ se basó en obtener valores de absorbancia cercano a 1.0, y el de C+ el $50 \%$ del valor de la absorbancia del $\mathrm{C}++$ a los 15 min. de la adición del sustrato-cromógeno. El suero control negativo (C) fue seleccionado en base a los resultados de ELISA-I de 4 sueros negativos de referencia, eligiéndose al suero que desarrolló la absorbancia más baja.

\section{Procedimiento de ELISA-I}

El antígeno específico de Brucella ovis diluido (1:400) en tampón de cubierta (tampón carbonato-bicarbonato $0.05 \mathrm{M} . \mathrm{pH}$ 9.6), fue distribuido en cada una de las celdas de la microplaca, en la cantidad de $100 \mathrm{ml} /$ celda, incubadas a $4^{\circ} \mathrm{C}$ toda la noche. Después de eliminar el exceso de la solución del antígeno, la microplaca fue lavada 3 veces con tampón de lavado (1 tableta de PBSTween disuelto en 500 de agua desionizadadestilada), la solución de lavado fue distribuida entre las celdas de la microplaca con la ayuda de un dispensador multicanal (Nunc immunowash).

Al final del último lavado, se dispensaron $100 \mu \mathrm{l}$ de sueros diluidos (1:200) en tampón diluyente (tampón fosfato salinoTween 0.01M. pH 7.4). Los sueros control fuertemente positivo, débilmente positivo y negativo fueron dispensados por cuadruplicado, y los sueros problema por duplicado. En cuatro celdas, no se dispensaron suero (placa blanco). La microplaca fue puesta en incubación por 1 hora a $37^{\circ} \mathrm{C}$ en agitación constante en una incubadora de microplacas (Denley- Labsystems). La microplaca fue lavada tres veces con buffer de lavado. Posteriormente se dispensaron a cada celda $100 \mu l$. del conjugado (globulina de conejo anti IgG ovino-peroxidasa) diluido 1:2000 en tampón diluyente, y se puso en incubación por una hora a $37^{\circ} \mathrm{C}$. Después de lavar tres veces, se dispensaron a cada celda $100 \mu 1$. de solución sustrato-cromógeno (2 tabletas de ABTS $+50 \mathrm{ml}$. de $\mathrm{H}_{2} \mathrm{O}_{2}$ disueltos en $950 \mathrm{ml}$ de buffer citrato-ácido cítrico $0.05 \mathrm{M} . \mathrm{pH} 4.5$ ). Finalmente la microplaca fue puesta en incubación a $37^{\circ} \mathrm{C}$ por 15 minutos. La reacción fue detenida agregando a cada celda $100 \mu$ l. de SDS al 4\%. Finalmente, la lectura fue realizada en un lector de ELISA (Multiskan-plus, Labsystems) utilizando un filtro de $405 \mathrm{~nm}$.

\section{Evaluación de ELISA-I}

Determinación del punto de corte.

El punto de corte, fue determinado mediante el análisis de las características del operador-receptor (ROC), utilizando el 
Software Exel Med Calc. Para lo cual se utilizaron los resultados del desarrollo de la absorbancia (DO) de los sueros positivos y negativos de referencia en ELISA-I transformados en por ciento de positividad (PP).

\section{Determinación de la sensibilidad y es- pecificidad diagnóstica.}

La sensibilidad y especificidad diagnóstica fueron estimadas insertando el punto de corte a los resultados (en porciento de positividad) de ELISA-I de los sueros positivos y negativos de referencia, para lo cuál se utilizó la tabla de $2 \times 2$, así como las fórmulas para hallar la sensibilidad y especificidad diagnóstica (Worthington et al., 1984). Se determinó el intervalo, de confianza al 95\% para los valores de sensibilidad y especificidad diagnóstica.

\section{Tesultutios}

\section{Preparación del antígeno de Brucella ovis}

El antígeno (extracto salino) de Brucella ovis, reaccionó positivamente con los anticuerpos séricos de carneros confirmados por aislamiento bacterial, en la prueba de inmunodifusión en gel (IDG). Esta prueba produjo una sola banda bien definida de precipitación. Así mismo este antígeno no reaccionó con suero de vacunos positivos a Brucella abortus ni de caprinos positivos a Brucella melitensis.

\section{Estandarización de ELISA-I}

Optimización de los reactivos biológicos.

Entre las diluciones 1:200 a 1:800 del conjugado, se observaron lecturas altas de densidad óptica $\left(\mathrm{DO}_{405} \geqslant 1.59\right)$ y un alto fondo inespecífico $\left(\mathrm{DO}_{405}>0.29\right)$. Las diluciones iguales o mayores a 1:6400, desarrollaron bajas lecturas de la absorbancia $\left(\mathrm{DO}_{405} \leqslant\right.$ 0.75 ), así como bajo fondo inespecífico.
Mientras que las diluciones 1:1600 y 1:3200 muestran DO máxima de 1.37 y 0.97 respectivamente, ambos con fondo inespecífico relativamente bajo $\left(\mathrm{DO}_{405}=0.29\right.$ y 0.22 , respectivamente). Estos parámetros son muy cercanos a lo requerido ( $\mathrm{DO}=1.0$ ), por lo que se eligió una dilución intermedia entre estas: 1: 2000. (Fig. 1).

Las diluciones 1:50 a 1:200 de antígeno, muestran lecturas altas del desarrollo de la absorbancia $\left(\mathrm{DO}_{405}>1.45\right)$, así como también alto fondo inespecífico ( $\left.\mathrm{DO}_{405}>0.20\right)$. Mientras que el desarrollo de la absorbancia de las diluciones mayores o iguales a 1:800 son cada vez más bajas $\left(\mathrm{DO}_{405}<0.83\right)$, pero también muestran bajo fondo inespecíficos $\left(\mathrm{DO}_{405}<0.16\right)$. Por otro lado, la dilución del antígeno 1:400 muestra un buen desarrollo de la absorbancia $\left(\mathrm{DO}_{405}=1.07\right)$ y un fondo inespecífico bajo $\left(\mathrm{DO}_{405}=0.17\right)$, siendo elegible para las fases subsiguientes de la estandarización de ELISA-I (Fig. 2).

Las diluciones del suero 1:50 y 1:100, desarrollan alta absorbancia $\left(\mathrm{DO}_{405}>1.59\right)$, muestran así mismo, alto fondo inespecífico $\left(\mathrm{DO}_{405} \geqslant 0.30\right)$. En tanto que diluciones del suero mayores o iguales a 1:400, muestran menor desarrollo de la absorbancia $\left(\mathrm{DO}_{405}\right.$ $<0.81$ ). Por otro lado, la dilución 1:200 muestra un buen desarrollo de la absorbancia $\left(D_{405}=1.06\right), y$ un fondo inespecífico relativamente bajo $\left(\mathrm{DO}_{405}=0.26\right)$. Por lo que, esta dilución fue considerada como la adecuada para ser utilizada rutinariamente (Fig. 3).

\section{Repetibilidad de ELISA-I}

Los valores de la absorbancia de las réplicas intraplaca de 12 sueros positivos, tuvieron coeficiente de variación (CV) entre $1.21 \%$ y $16.07 \%$, y la mayor parte de estos valores fueron menores al 10\% (Cuadro 1). Por su parte, los valores de la absorbancia de los mismos sueros entre los ensayos (interplaca), tuvieron $\mathrm{CV}$ entre $7.08 \%$ y $17.84 \%$ (Cuadro 2). 


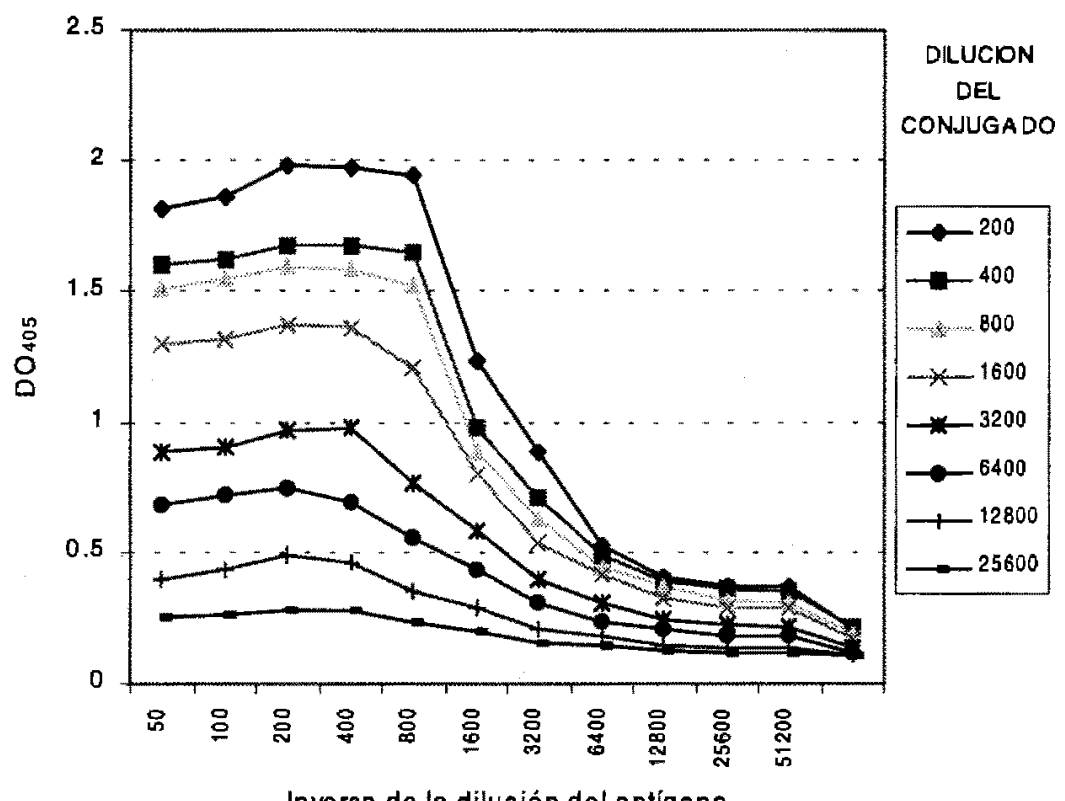

Inversa de la dilución del antígeno

Figura 1. Titulación del conjugado IgG conejo anti ovino - peroxidasa

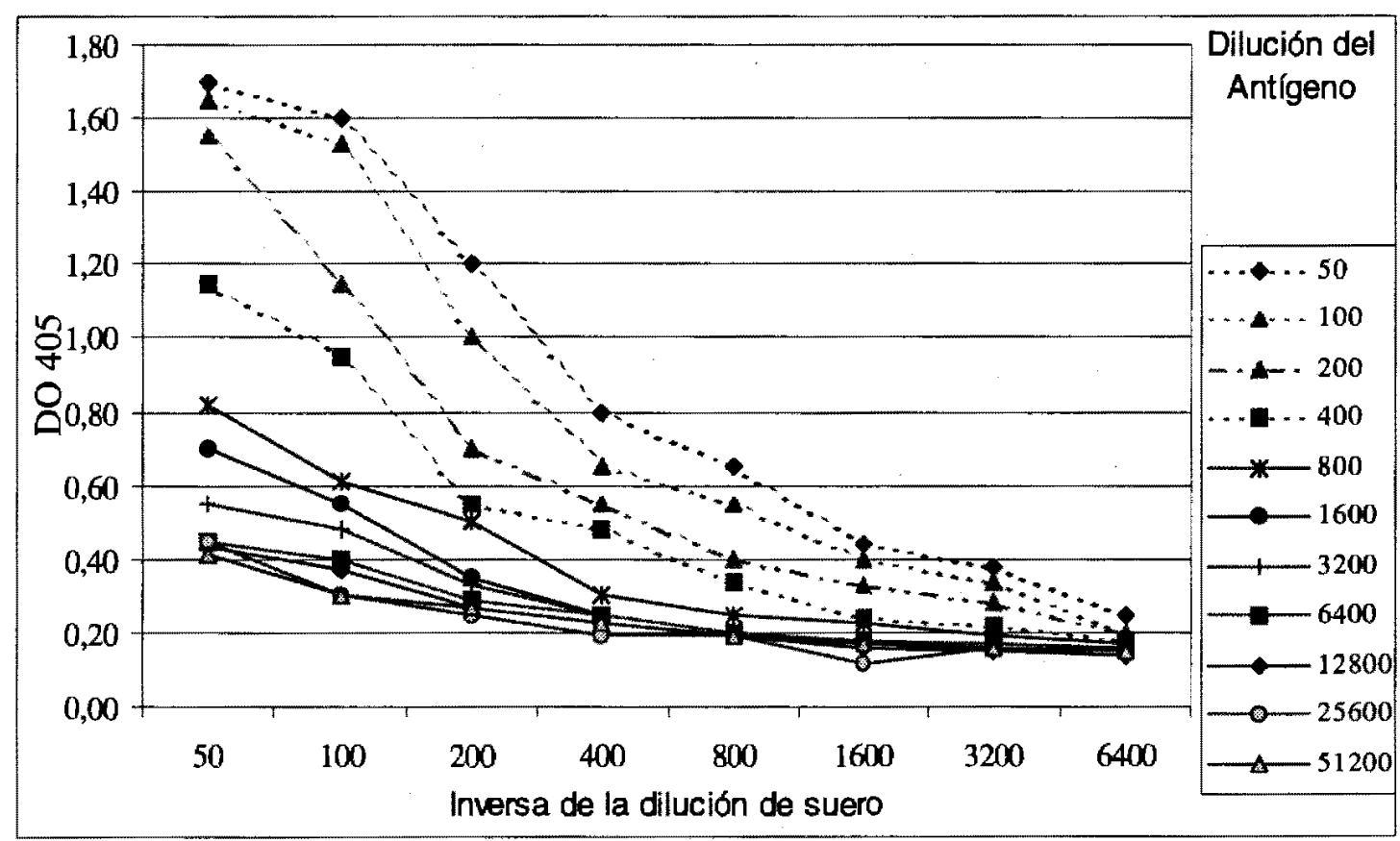

Figura 2. Titulación del antígeno (extracto salino) de B. ovi. 


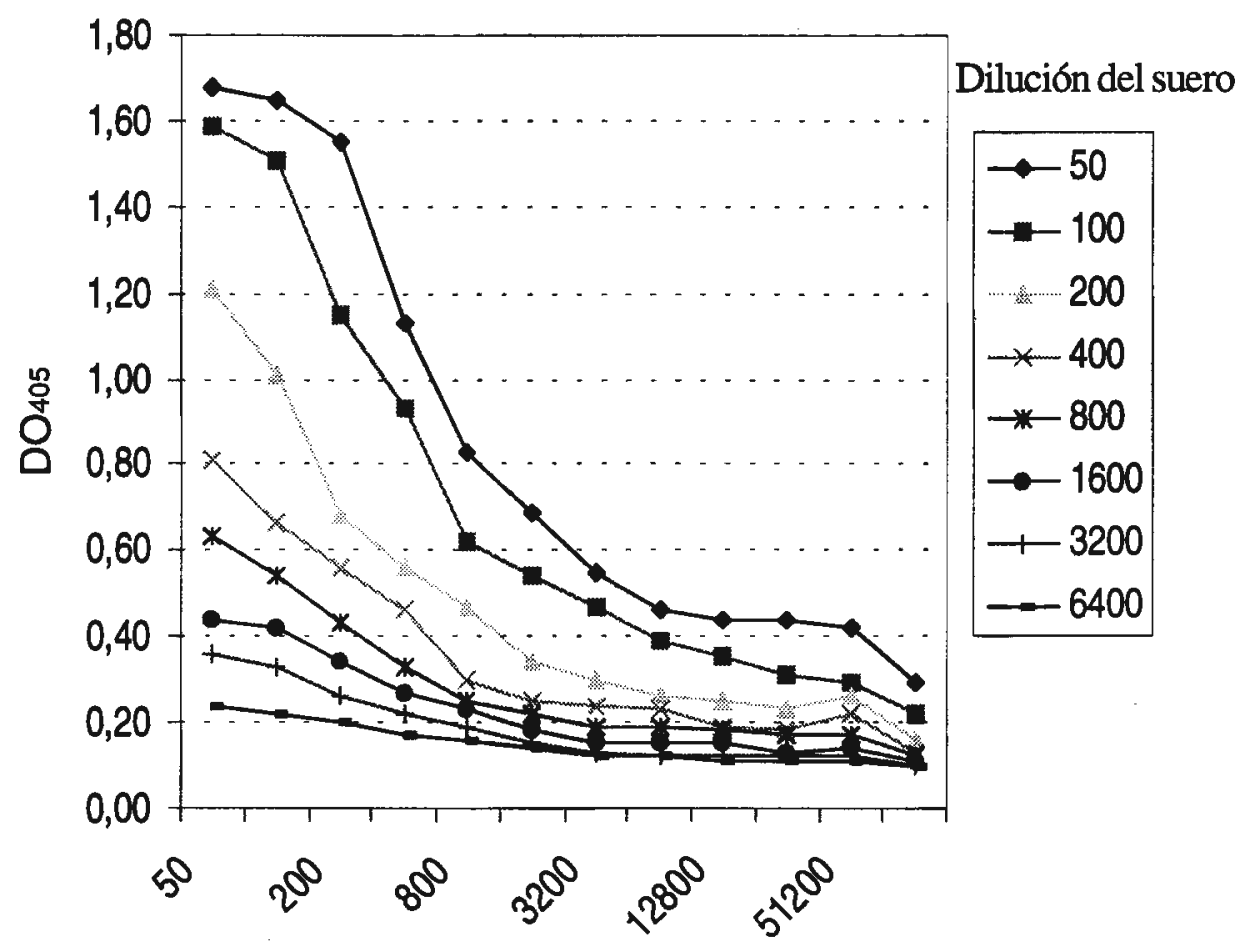

Inversa de la dilución del antígeno

Figura 3. Titulación del suero ovino positivo a anticuerpos contra B. ovis.

Cuadro 1. Variabilidad (CV) intraplaca (8 replicas) de la absorbancia $\left(\mathrm{DO}_{405}\right)$ de 12 sueros positivos a anticuerpos contra B.ovis, en ELISA-I.

\begin{tabular}{|c|c|c|c|c|c|c|c|}
\hline \multirow{2}{*}{ Suero \# } & \multicolumn{6}{|c|}{ Microplaca \# } & \multirow{2}{*}{ Rango } \\
\hline & 1 & 2 & 3 & 4 & 5 & 6 & \\
\hline 1 & 5.33 & 5.03 & 6.89 & 8.12 & 4.15 & 2.71 & $2.71-8.12$ \\
\hline 2 & 4.87 & 3.73 & 5.57 & 3.81 & 5.13 & 5.34 & $3.73-5.57$ \\
\hline 3 & 6.03 & 9.81 & 4.39 & 2.98 & 4.33 & 6.68 & $2.98-9.81$ \\
\hline 4 & 8.89 & 6.13 & 5.48 & 4.44 & 3.71 & 2.31 & $2.31-8.89$ \\
\hline 5 & 4.47 & 5.95 & 2.12 & 4.82 & 6.15 & 1.21 & $1.21-6.15$ \\
\hline 6 & 9.22 & 9.81 & 4.8 & 4.35 & 5.89 & 3.13 & $3.13-9.81$ \\
\hline 7 & 6.03 & 3.69 & 5.47 & 4.66 & 4.08 & 3.19 & $3.19-6.03$ \\
\hline 8 & 2.67 & 3.81 & 4.69 & 5.46 & 7.38 & 2.42 & $2.42-7.38$ \\
\hline 9 & 7.02 & 11.26 & 3.28 & 7.98 & 4.15 & 3.1 & $3.10-11.26$ \\
\hline 10 & 10.96 & 4.16 & 5.04 & 5.76 & 5.46 & 8.61 & $4.16-10.96$ \\
\hline 11 & 13.83 & 16.07 & 8.46 & 7.2 & 4.94 & 3.15 & $3.15-16.07$ \\
\hline 12 & 3.75 & 9.34 & 10.37 & 5.84 & 7.22 & 4.22 & $3.75-9.34$ \\
\hline
\end{tabular}


Cuadro 2. Promedio de absorbancia $\left(\mathrm{DO}_{405}\right)$ y desviación estándar (5), variabilidad $(\mathrm{CV})$ interplaca (6 replicas) de 12 sueros positivos a anticuerpos contra B.ovis en ELISA - I.

\begin{tabular}{cccc}
\hline Suero \# & DO Prom & S & CV \\
\hline 1 & 0.95 & 0.1281 & 13.45 \\
2 & 1.01 & 0.0716 & 7.08 \\
3 & 0.99 & 0.1184 & 11.92 \\
4 & 1.27 & 0.1927 & 15.70 \\
5 & 0.99 & 0.0792 & 8.00 \\
6 & 1.38 & 0.1874 & 13.52 \\
7 & 1.04 & 0.0967 & 9.25 \\
8 & 0.66 & 0.1180 & 17.84 \\
9 & 1.05 & 0.0884 & 7.68 \\
10 & 0.44 & 0.0374 & 8.50 \\
11 & 0.53 & 0.1034 & 15.95 \\
12 & 0.57 & 0.0890 & 15.58 \\
\hline
\end{tabular}

\section{Determinación de los sueros con-} trol

Se eligió como control fuertemente positivo $(\mathrm{C}++)$ al suero $\mathrm{N}^{\circ} 9$, cuyo valor del desarrollo de la absorbancia fue 1.05 , y como control débilmente positivo $(\mathrm{C}+)$ fue seleccionado el suero $\mathrm{N}^{\circ} 11$, cuya DO fue 0.53 (Cuadro 2). Los valores del desarrollo de aborbancia de los cuatro sueros negativos de referencia (Cuadro 3) permitieron la selección del suero $\mathrm{N}^{\circ} 22$ control negativo (C-) que produjo el valor más bajo de absorbancia ( $\mathrm{DO}=0.10$ ).
El desarrollo de la absorbancia del suero control débilmente positivo $(\mathrm{C}+)$ fue equivalente al $50.48 \%$ del control fuertemente positivo, y el del suero control negativo (C-) fue $9.52 \%$ del control fuertemente positivo (Cuadro 4).

Evaluación de la aplicación de ELISA-I.

\section{Determinación del punto de corte}

El análisis de las características del operador-receptor (ROC) de los valores de

Cuadro 3. Absorbancia $\left(\mathrm{DO}_{405}\right)$ de cuatro sueros de referencia negativos a anticuerpos contra B.ovis en ELISA-I

\begin{tabular}{|c|c|c|c|c|c|}
\hline \multirow{2}{*}{ Suero $\mathrm{N}^{\circ}$} & \multicolumn{4}{|c|}{ Réplicas } & \multirow{2}{*}{$\overline{\mathrm{X}}$} \\
\hline & 1 & 2 & 3 & 4 & \\
\hline 59 & 0.170 & 0.203 & 0.192 & 0.158 & 0.18 \\
\hline 22 & 0.092 & 0.108 & 0.097 & 0.112 & 0.10 \\
\hline 1 & 0.126 & 0.128 & 0.145 & 0.126 & 0.13 \\
\hline 9 & 0.135 & 0.145 & 0.129 & 0.153 & 0.14 \\
\hline
\end{tabular}


Cuadro 4. Comparación de la absorbancia $\left(\mathrm{DO}_{405}\right)$ en ELISA-I de los sueros control debilmente positivos (C+) y negativo (C-) con el control fuertemente positivo ( $\mathrm{C}++$ ).

\begin{tabular}{clcc}
\hline$\#$ & \multicolumn{1}{c}{$\begin{array}{c}\text { Suero } \\
\text { control }\end{array}$} & $\begin{array}{c}\mathrm{DO}_{405} \\
\text { promedio }\end{array}$ & $\begin{array}{c}\text { \% de } \mathrm{DO}_{405} \text { con } \\
\text { respecto a C++ }\end{array}$ \\
\hline 4 & Fuertemente positivo (C++) & 1.05 & $-\cdots$ \\
11 & Débilmente positivo (C+) & 0.53 & 50.48 \\
22 & Negativo ( C-) & 0.1 & 9.52 \\
\hline
\end{tabular}

porciento de positividad (PP) de 74 muestras positivas de referencias y 75 muestras de negativas de referencia, mediante el software EXCEL, MED CALC, dio como resultado que el umbral entre positividad y negatividad (punto de corte) se encuentra en 23.89 PP. De modo que valores del PP de los sueros de referencia mayores a dicho valor, fueron considerados positivos a la prueba ELISA-I, en tanto que valores menores al mismo fueron considerados negativos.

\section{Determinación de la sensibilidad y especificidad diagnóstica}

De 74 muestras positivas, 72 fueron clasificadas como verdaderas positivas y 2 como falsos negativas. De 75 muestras negativas, 74 fueron catalogadas como verdaderas negativas y 1 como falso positiva. Estos datos al ser procesados en la tabla $2 \mathrm{x}$ 2 dieron por resultado una sensibilidad diagnóstica del $97.3 \%$, y una especificidad diagnóstica de $98.6 \%$, cuyos valores de intervalo de confianza al $95 \%$ resultaron entre 90.6 - 99.6 y de $92.8-99.8$, respectivamente.

\section{Discusión}

La técnica de obtención del antígeno (extracto salino) de Brucella ovis así como la estandarización y validación de una prueba de ELISA-I para el diagnóstico de brucelosis ovina, evidencia la aparente realización y replicación de la prueba en cualquier laboratorio de diagnóstico equipado con lector de ELISA.

La técnica de obtención del extracto salino de Brucella ovis, fue utilizada por Alton (1976), Walker et al. (1985), Alonso et al (1995), OIE (1996), y Torres-Nuñes et al. (1998). Existen alternativas de preparación antigénica, algunos consideran una etapa de ultracentrifugación entre 80.000 y $100.00 \mathrm{x}$ g. a $4^{\circ} \mathrm{C}$ en el proceso de purificación del extracto salino. Sin embargo, otros (Alton, 1975; Walker et al., 1995) lo consideran no necesario. La ultracentrifugación fue omitida en este estudio sin afectar la calidad del antígeno. Por otro lado, el almacenamiento del antígeno en congelamiento $\mathrm{a}-20^{\circ} \mathrm{C}$, procedimiento adoptado en la realización del presente trabajo, es una buena alternativa reportada por Alton (1975), Walker et al. (1985) y Alonso et al. (1995) para laboratorios que carecen de equipo de liofilización. El reactivo puede, sin embargo almacenarse liofilizado (OIE, 1996; Torres-Nuñez et al., 1998).

El extracto salino, denominado también, antígeno específico de Brucella ovis, está constituido básicamente por lipopolisacáridos rugosos (LPS-R) y de proteínas componentes de la membrana exterior del germen. El extracto salinico es considerado como el mejor antígeno para el diagnóstico serológico de la brucelosis ovina (Spencer y Burges, 1984; OIE, 1996). 
El procedimiento de la titulación de los reactivos biológicos (conjugado, antígeno y suero) mediante el método denominado "tablero de ajedrez", es una técnica ampliamente utilizada en estandarización de pruebas de ELISA (Afzal et al., 1984; Cárdenas y Maki, 1986; Coligan et al., 1992), realizándose la lectura de la absorbancia (DO). 15 minutos después de la adición del sustrato-cromógeno. Este tiempo de reacción está indicado en el Manual del kit ELISA-I para brucelosis (LAEA/FAO, 1994) que utiliza soluciones y tampones similares, y se encuentra en el rango de tiempo (10 -20 minutos) señalado por Nielsen et al., (1996) para las pruebas de ELISA en brucelosis.

En la titulación de los reactivos biológicos, se consideró dilución óptima, a aquella que produjo un buen desarrollo de la absorbancia (DO cercano a 1.0) y un valor más bajo de fondo inespecífico en el tiempo estipulado (10 a 20 minutos) (Walker $e t$ al., 1985; Calamel y Lambert, 1988; Nielsen $e t$ al., 1996). Acorde con este principio, las diluciones óptimas del conjugado, antígeno y suero $(1: 2000,1: 400$ y $1: 200$ respectivamente), determinadas en el presente trabajo, estuvieron enmarcadas en este rango.

Las diluciones más bajas tanto del conjugado, como del antígeno y del suero, desarrollaron altos valores de la absorbancia. Esto se debe al efecto del exceso del reactivo (Crowther y Smith, 1992), que tiende a aglomerarse en vez de interactuar uniformemente con el reactivo de su afinidad (Nielsen $e t$ al., 1996; Calamel y Lambert, 1988). Al mismo tiempo estas diluciones mostraron valores altos de fondo inespecífico, por tanto, estas diluciones fueron consideradas inadecuadas para el uso rutinario en ELISA. Por otro lado, las diluciones más altas de cualquiera de los reactivos señalados, mostraron valores bajos de la absorbancia. Este fenómeno se debe a la escasez del reactivo e implícitamente causa pérdida de la sensibilidad del mismo, por lo tanto son incompatibles para su uso en ELISA (Crowther y Smith, 1992; Calamel y Lambert, 1988).
La dilución del conjugado globulina de conejo anti IgG ovino-peroxidasa ( $1: 2000)$, considerada como óptima, es un valor cercano a los datos reportados por investigadores que trabajaron con reactivo similar: $1: 1500$ (Worthington et al., 1984); 1:3000 (Walker et al., 1985); 1:2500 (Alonso y Guzmán, 1995). Existe variabilidad de datos sobre la dilución del extracto salino Brucella ovis reportados por autores que trabajaron con este tipo de antígeno: 1:100 (Walker et al., 1985), 1:800 (Spencer y Burges, 1984), 1:2000 (Worthington et al., 1984). La dilución óptima del antígeno determinado en el presente trabajo (1:400), se encuentra entre estos valores, esta dilución contiene una concentración de $1 \mathrm{mg} / \mathrm{ml}$. de extracto salino (Alonso y Guzmán, 1995). En tanto que la dilución óptima del suero 1:200, es ampliamente concordante con los datos reportados en trabajos similares (Spencer y Burges, 1984; Alonso y Guzmán, 1995; OIE, 1996). Pero difiere ligeramente con lo indicado por Worthington $e t$ al. (1984) 1:150.

La repetibilidad del ensayo, es un indicador de la precisión de la prueba. Una menor dispersión de los resultados de las réplicas es señal de una buena repetibilidad (OIE, 1996). El coeficiente de variación (CV) de la mayor parte de las réplicas intraplaca de los 12 sueros, tuvieron valores menores al $10 \%$ aún cuando varían entre $1.21 \%$ y $16.07 \%$. Por otro lado, los valores del coeficiente de variación (CV) de las réplicas interplaca, se encuentran entre el $7.08 \%$ y $17.84 \%$. Estos valores del $\mathrm{CV}$ intra e interplaca son menores al límite aceptable: $20 \%$ (Nielsen et al., 1996). Por tanto, los estimados de la variabilidad (repetibilidad) intra e interplaca determinados en el presente trabajo se encuentran dentro del límite señalado. Todo esto indica que la prueba estandarizada tiene la capacidad de proveer resultados repetibles dentro y entre los ensayos.

Los sueros control fueron seleccionados en base a su reactividad en ELISA-I. El suero control fuertemente positivo $(\mathrm{C}++) \mathrm{de}$ sarrolló absorbancia $\mathrm{DO}_{405}=1.05$ que es cer- 
cano a lo recomendado para las pruebas de ELISA en brucelosis (DO =1) (Crowther y Smith, 1992). Por su parte el suero control débilmente positivo $(\mathbf{C}+)$ produjo absorbancia $\left(\mathrm{DO}_{405}=0.53\right)$ equivalente aproximadamente a la mitad $(50.48 \%)$ del valor del sero fuertemente positivo, en tanto que el suero control negativo (C-) desarrollo absorbancia $\left(\mathrm{DO}_{405}=0.10\right)$ equivalente al $9.52 \%$ del suero control fuertemente positivo. Todos estos datos son concordantes con las recomendaciones para ELISA (Crowther y Smith, 1992; Nielsen et al., 1996).

La sensibilidad y especificidad diagnóstica son parámetros que permiten valorar la capacidad del ensayo estandarizado para identificar y/o diferenciar animales enfermos y no enfermos (Martín et al., 1984). Estos estimados deben ser derivados de los resultados de muestras de animales cuyo estado de infección (animales enfermos y animales no enfermos) sean conocidos con precisión (OIE, 1996). Para el efecto, las muestras positivas de referencia procedieron de carneros con epididimitis clínica y cuyo estado de infección fue confirmada por aislamiento bacterial. Este procedimiento es considerado como el "estándar de oro" para la determinación de la sensibilidad diagnóstica de una prueba (Jacobson, 1992; Nielsen et al., 1996; OIE, 1996). Mientras que los sueros negativos de referencia procedieron de un rebaño de una zona no endémica de brucelosis ovina (distrito de Cieneguilla - Lima). Estas muestras procedieron de animales sin ningún tipo de lesión epididimal y/o testicular y fueron negativos a anticuerpos de Brucella ovis en IDG.

La curva ROC, representa el compromiso entre la fracción verdaderamente positiva (FVP) y la fracción de falsos positivos (FFP) de las muestras de referencia, señalando el punto de corte (Nielsen et al., 1996). El punto de corte es un estimado que reduce los datos generados por el procesamiento de las muestras de referencia en dos categorías: positivas o negativas, según el resultado de la absorbancia desarrollada por cada muestra transformada en términos de porciento de positividad (PP) (Calamel y Lambert, 1988; Martín et al., 1984). La inserción del punto corte (23.88 PP) a los resultados de ELISA-I de los sueros de referencia, categorizó 72 de 74 sueros positivos de referencia como verdaderos positivos y 2 como falsos negativos (sensibilidad diagnóstica $=97.3 \%$ ). Esto indica que la prueba estandarizada tiene la capacidad de identificar con precisión el $97.3 \%$ de ovinos infectados o enfermos de brucelosis ovina, la diferencia (2.7\%) quedan erróneamente clasificados como sanos o no infectados. Por otro lado, 74 de 75 sueros negativos de referencia fueros categorizados como verdaderos negativos y 1 como falso positivo (especificidad diagnóstica $=98.6 \%$ ). Todo esto, es una característica intrínseca de la prueba estandarizada de identificar correctamente al 98.6\% de animales no infectados por Brucella ovis, y al $1.4 \%$ de animales no infectados los cataloga equivocadamente como infectados.

Los valores de la sensibilidad y especificidad diagnóstica encontrados, son similares a los parámetros reportados por Worthington et al. (1984): $97.2 \%$ y $98.6 \%$ respectivamente; Walker et al. (1985): 100\% para ambos estimados, quienes trabajaron con extracto salino; en tanto que Afzal et al. (1984) reportó valores de 94.7 y 95.7 para la sensibilidad y especificidad trabajando con antígenos obtenidos por sonicación y de 94.7 y $100 \%$ cuando utilizó LPS.

Los valores de la sensibilidad y especificidad diagnóstica obtenidos son marcadamente superiores a los correspondientes a la prueba de fijación del complemento: $91 \%$ y $93 \%$ (Véliz et al., 1973) y a la sensibilidad diagnóstica de la prueba de inmunodifusión en gel (IDG): $91.7 \%$ (Worthington et al., 1984). Consecuente, esta prueba estandarizada (ELISA-I), resulta ventajosa frente a estas pruebas. Adicionalmente, para IDG se requiere gran cantidad de antígeno, tal como fue observado en los trabajos previos a la estandarización de ELISA. 
En tanto que para esta última, son necesarias pequeñas cantidades de reactivos biológicos tales como antígeno y conjugado, los que corrientemente están limitadamente disponibles. Por otro lado la prueba de ELISA, puede ser automatizada permitiendo procesar gran cantidad de muestras.

\section{Conclusiones}

El extracto salino (LPS-R) de Brucella ovis utilizado como antígeno, mostró buena performance en la detección de anticuerpos de contra Brucella ovis en ELISA-I.

Los parámetros estandarizados encontrado para ELISA-I fueron: dilución del conjugado globulina de conejo anti IgG ovinoperoxidasa 1:2000, dilución del antígeno (extracto salino) de Brucella ovis 1: 400 y dilución de los sueros 1: 200.

La prueba de ELISA-I, demostró una elevada sensibilidad $(97.3 \%$ ) y especificidad (98.6\%) para el diagnóstico de la epididimitis a Brucella ovis.

\section{Agravecimiento}

Los autores agradecen al Laboratorio de Microbiología y Parasitología de la FMV UNMSM. Especialmente a los Drs. Hermelinda Rivera, Alberto Manchego y Maria Cerón por su valiosa colaboración en el desarrollo del presente trabajo.

\section{Literatura Citada}

1. Alton, G.G., L.M. Jones, D.E. Pietz. 1975. Laboratory techniques in brucellosis 2th. World Health Organisation. Geneva. p. 114 - 148.

2. Ameghino, E. 1988. Avances en investigación en salud animal - ovinos. Bol. Divul. IVITA. Lima - Perú, p. 4148.
3. Afzal, M., R. Tengerdy, P.G. Squire y R.P. Elis. 1984. Characterization of Brucella ovis lipopolisacharide and its use for diagnosis of ram epididymitis by enzyme-linked immunosorbent assay. J. of Clin. Microbol. 6:1159-1164.

4. Alonso, O., N.V. Rojas y E. Guzmán. 1995. Uso de una técnica de ELISA indirecta para el diagnóstico de brucelosis ovina, en Arch. De Med. Vet. Vol. Extraordinario. Fac. C.V. Univ. Austral de Chile, Valdivia. p. 113-117.

5. Blaha T. 1995. Epidemiología especial veterinaria 2da. Ed. Edit. Acribia. Zaragoza, p. 209-210.

6. Cárdenas, A.L. y R.L. Maki. 1986. Detectión of antibody in rams with contagious epididymitis using the enzymelinked immunosorbent assay. Am. J. Vet. Res. 47:738-739.

7. Calamel, M. y M. Lambert. 1988. ELISA standarized technique. English De. Laboratoire National Pathologie des Petits Ruminants et des Abielles. Nice Frace. p. 45-108.

8. Coligan., J.E., A.M. Kruisbeek, D.H. Margulies, E.M. Shevach y W. Strober. 1992. Current protocols in immunology. Vol. 1 p. 215 .

9. Crowther, J.R. y H. Smith. 1992. ELISA Manual U.K.p.2-21.

10. Guerrero, J. y G. Calderón. 1985. Modelos experimentales para el estudio de la relación hospedero-parásito. 1ra. UNMSM-IVITA-American society for microbiology. p.56-59

11. Homse, A.C., A.P. Casaro, C.M. Campero, F. Paolicchi y H. Terzolo. 1992. Infección experimental en ovejas por Brucella ovis Rev. Med. Vet.75(4):304-305.

12. Jacobson, R.H. 1992. How well do serodiagnostic tests predict the infection of disease status on animals? Regional network, for latín amerca on animal disease diagnosis using immunoassay and labelled DNA probe techniques. IAEA. Costa Rica p. 31-41.

13. Jub K.V.F. y P.C. Kennedy. 1993. Pathology of domestic animals. Vol. 3. 
Academic Press. Inc. San Diego Cal. USA. p. 396-400.

14. IAEA/FAO. Programme. Animal production and health. 1994. Brucellosis indirect ELISA kit. p. 10-19.

15. Martin, S.W., Wedell, W., Penrose, M.E. 1984. A comparison of trhee serological tests for the diagnosis of Brucella ovis infection in rams. V.M.J. p. 71-74.

16. Nielsen, K., D.E. Gall, W.A. Kelly, A.M. Vigliocco, M.D. Henning y M.M. García. 1996. Desarrollo del inzimoinmunoensayo para el diagnóstico de la brucelosis. Valdivia, Chile.p. 6.111.5

17. OIE Manual of standards for diagnostic tests and vaccines. 1996. París, Francia. p. 8-13.

18. Paolicchi, F.A., J.. Bartolomé, A. Patitucci, C. Solanet y C.M. Campero. 1992. Seguimiento clínico, serológico y bacteriológico en carneros naturalmente infectados con Brucella ovis Rev. Med.: Vet. 73(1):46-51.

19. Rahaley, R.S., S.M. Dennis, y M.S. Smeltzer. 1984. Comparison of the enzyme-linked immunosorbent assay and complement fixation test for detecting Brucella ovis antibodies in sheep. The. Vet. Rec.12:467-470.

20. Robles, C.A. 1995. Epididimitis contagiosa de los carneros por Brucella ovis Rev. Med. Vet. 79(1):67-71.

21. Rosadio, R.H. 1978. Posible eliminación de la cepa vacunal REV1 en las secresiones o excresiones de ovinos. Vet. y Zoot. 30(85/68): 12.

22. Spencer, T.L. y G.W. Burges. 1984. Enzume-linked immunosorbent assay for Brucella ovis specific antibody in ram sera. Res. in Vet. Science. 36:194-198.

23. Sumption, K.J. 1996. ELISA test for antibody detection in veterinary diagnosis: execises and examples. Central for Tropical Vet. Med. University of Edingurg.p. 1-7.

24. Torres-Nuñez, E., E. Diaz-Aparicio, V. Tenorio y L. Hernández. 1998. Stability of antigen and agarose used in a double immunodofusión serologic test for Brucella ovis J. Vet. Diagn. Invest. 10(1):113-115.

25. Veliz, N., E. Ameghino y R.H. Rosadio. 1973. Método comparativo entre inhibición de la aglutinación y fijación del complemento para detectar anticuerpos anti Brucella ovis Rev. Inv. Pec. IVITAUNMSM 2:169-172.

26. Walker, R.L., B.R. Lea Master, J.N. Srellflug y E.L. Riberstein. 1985. Use of enzyme-liked immunosorbent assay for detection of antibodies to Brucella ovis in sheep: field trial. Am. J. Vet. Res. 8:1642-1643.

27. Worthington, R.W., W. Wedell y M.E. Penrose. 1984. A comparison of three serological tests for the diagnosis of Brucella ovis infection in rams. VM-J. 12:160-163. 